\title{
LOS EFECTOS SONOROS EN LAS SERIES RADIOFÓNICAS: EL CASO DE LA SERIE POLICÍACA TAXI KEY
}

\section{Sound Effects in Radio Series: The Case of the Taxi Key Police Series}

\section{Os efeitos sonoros nas séries radiofônicas: o caso da série policial Taxi Key}

Elisa Arias García, Universidad Pontificia de Salamanca (España)

eariasga@upsa.es

Recibido: 15 de enero de 2018

Aprobado: 11 de mayo de 2018

\section{RESUMEN}

Los efectos sonoros en las series radiofónicas cumplen una función esencial en la recreación de los escenarios y acciones, contribuyen a otorgar verosimilitud a las escenas representadas y favorecen la generación de imágenes mentales en el oyente, tanto desde una perspectiva denotativa como connotativa. En el presente artículo se plantea el análisis de un caso concreto, el correspondiente a la serie policíaca Taxi Key. Entre los objetivos del estudio se encuentran: identificar y describir las principales funciones que desempeñan los efectos sonoros en los guiones de la serie, así como su vinculación con el género policíaco y la ambientación de misterio; establecer si existe evolución en cuanto al número de efectos empleados en función de las diversas etapas del seriado; determinar cuáles son los efectos de sonido más frecuentes en los capítulos analizados. Los resultados ponen de manifiesto que en la serie Taxi Key prevalece la función descriptivo-ambiental, aunque estén presentes la narrativa y la expresiva. La primera etapa de la serie es la que registra una mayor diversidad de efectos sonoros.

Palabras clave: ficción, serie radiofónica, efectos sonoros, Taxi Key, policíaco. 


\section{ABSTRACT}

The sound effects in the radio series fulfill an essential function in the recreation of scenarios and actions. They also contribute to grant credibility to the scenes represented and favor the generation of mental images for the listener, from both denotative and connotative perspectives. In the present article, the analysis of a specific case is presented: the one corresponding to the Taxi Key police series. Among the objectives of the study we find the following: to identify and describe the main functions played by sound effects in the scripts of the series, as well as its connection with the detective genre and mystery setting; to establish the existence (if that is the case) of any evolution in terms of the number of effects used depending on the various stages of the series, as well as to determine which are the most frequent sound effects in the chapters analyzed. The results show that in the Taxi Key series the descriptive-environmental function prevails, although narrative and expressive functions are also present. The first stage of the series is the one that registers a greater diversity of sound effects.

Keywords: Fiction, radio series, sound effects, Taxi Key, detective genre.

\section{RESUMO}

Os efeitos sonoros nas séries radiofônicas cumprem uma função essencial na recreação dos cenários e ações, contribuem a outorgar verossimilitude às cenas representadas e favorecem a geração de imagens mentais no ouvinte, tanto desde uma perspectiva denotativa quanto conotativa. No presente artigo apresenta-se a análise de um caso concreto, o correspondente à série policial Taxi Key. Entre os objetivos do estudo encontram-se: identificar e descrever as principais funções que desempenham os efeitos sonoros nos roteiros da série, assim como sua vinculação com o gênero policial e a ambientação de mistério; estabelecer se existe evolução em quanto ao número de efeitos empregados em função das diversas etapas do seriado; determinar quais são os efeitos de som mais frequentes nos capítulos analisados. Os resultados põem de manifesto que na série Taxi Key prevalece a função descritivo-ambiental, ainda que estejam presentes a narrativa e a expressiva. A primeira etapa da série é a que registra uma maior diversidade de efeitos sonoros.

Palavras-chave: ficção, série radiofônica, efeitos sonoros, Taxi Key, policial.

\section{Introducción}

Como afirman Pousa y Yaguana (2013), "la vida está compuesta por sonidos" (p. 13). De esta forma, "los efectos sonoros forman parte de la composición escénica de cada actividad que realizamos" (Pousa y Yaguana, 2013, p. 71). El hecho de que estos sean una constante en nuestro día a día explica, en gran medida, la relevancia que 


\section{DISERTACIONES}

ESTUDIOS

El papel del sonido en la comunicación: contribución, funciones y efectos

ISSN: $1856-9536$

Doi: http://dx.doi.org/10.12804/revistas.urosario.edu.co/disertaciones/a.6403

Volumen 12, Número 2 / Julio-diciembre 2019

Versión PDF para imprimir desde

http://revistas.urosario.edu.co/index.php/disertaciones

adquiere su presencia en los relatos sonoros, pues proporcionan al oyente una herramienta idónea para imaginar lo narrado: "Los resultados de diversas investigaciones constatan que un mensaje radiofónico complejo, que emplee varios recursos sonoros, presenta más probabilidades de generar imágenes mentales, especialmente cuando se emplean efectos de sonido y planos sonoros" (Rodero, 2011, p. 1).

A pesar de que, por lo general, el empleo de la palabra radiofónica sea el elemento prioritario en la construcción del guion de una serie en radio, los efectos sonoros y la música se erigen como sistemas expresivos de relevancia, pues contribuyen a que el oyente se sumerja en el universo creado para cada episodio, al otorgar verosimilitud a las escenas, provocar sensaciones, facilitar las transiciones, dinamizar el ritmo del relato... "Todo va encaminado a conseguir que, al cerrar los ojos, el oyente consiga trasladarse a ese mundo y se mueva por él del modo en que los personajes de la historia lo hacen; que se sienta dentro de ella y rodeado por el sonido. Por ello, la ficción sonora es una sinfonía de sonidos que deben estar perfectamente coreografiados: palabra, ambientación musical, efectos sonoros, ritmo, tonos y planos sonoros" (Aguilera \& Arquero, 2017, pp. 119-120).

El poder evocador del sonido a través de las ondas otorga al emisor el privilegio de indagar en la imaginación de su audiencia. ${ }^{1}$ Es en este ámbito en el que la ficción sonora ocupa un lugar de excepción al explotar los múltiples recursos de los que dispone la radio, entre los que se encuentran los efectos sonoros.

En el presente artículo nos centraremos en un género específico: la serie radiofónica. En un elemento del lenguaje radiofónico concreto: los efectos sonoros. Y en un caso: Taxi Key.

\section{Los efectos sonoros en las series radiofónicas}

Si nos detenemos en el objeto de estudio que nos ocupa, los efectos sonoros de la radio, podemos concebirlo como el "conjunto de formas sonoras representadas por sonidos inarticulados o de estructura musical, de fuentes sonoras naturales y/o artificiales, que restituyen objetiva y subjetivamente la realidad construyendo una imagen" (Balsebre, 2007, p. 125). Por lo tanto, cada tipo de efecto puede ser clasificado según su naturaleza sonora y la función que desempeña.

Encontramos diversas tipologías a través de las que poder catalogar y caracterizar los efectos sonoros. En primer lugar, aquellas en las que se establece un vínculo entre el efecto de sonido y aquello que representa, ya que "la congruencia en la asociación de la forma sonora con la imagen que representa será el parámetro básico que regulará la definición de las dimensiones del efecto sonoro" (Balsebre, 2007, p. 123). Desde un punto de vista semiótico, Merayo y Pérez (2001) definen los efectos como "secuencias sonoras que designan una realidad reconocible por cualquier oyente, actuando bien como sustitutos o simuladores de realidades físicas, o bien con un carácter convencional o arbitrario" (p. 52). Aparece en este contexto el binomio de efectos reales/irreales (Guarinos, 2009; Martínez-Costa y Díez Unzueta, 2005), en función de si el sonido que se produce representa algo que existe, o no, en la realidad -a lo que podríamos llegar a añadir: si existe, o no, en la realidad con unas características sonoras similares-.

1 "[...] Cualquier forma de audiodrama debe, en la medida de lo posible, dar a la audiencia, al público, la sensación de que asiste a los hechos que se refieren" (Ortiz Sobrino \& Volpini, 2017, p. 19). 


\section{DISERTACIONES}

ESTUDIOS

El papel del sonido en la comunicación: contribución, funciones y efectos

ISSN: $1856-9536$

Doi: http://dx.doi.org/10.12804/revistas.urosario.edu.co/disertaciones/a.6403

Volumen 12, Número 2 / Julio-diciembre 2019

Versión PDF para imprimir desde

http://revistas.urosario.edu.co/index.php/disertaciones

Desde esta perspectiva, Soengas (2010) establece una distinción entre los efectos sonoros diegéticos, a los que define, igualmente, como "aquellos que representan algo que existe en la realidad, por ejemplo el ladrido de un perro" (p. 176), de los efectos extradiegéticos, que conceptualiza como "todos los que representan algo que no existe en la realidad. Se trata de sonidos para los cuales el ser humano no tiene referente en la realidad" (Soengas, 2010, p. 177). La denominación utilizada por este autor, diegético/extradiegético, podría ser empleada a su vez para determinar la relación que existe entre el efecto sonoro y la historia representada en cada episodio de una serie. En este caso podríamos considerar efectos de sonido diegéticos a aquellos que forman parte de la historia narrada (timbre de la vivienda de uno los protagonistas, tic-tac del reloj de un personaje, sonido del mar en una playa desierta...) y extradiegéticos a los sonidos que no pertenecen al universo narrado, pero cumplen una función determinada en el capítulo (efecto de cierre del episodio semanal, efecto sonoro que indique el paso del tiempo y favorezca la transición entre escenas...).

En función del tipo de género al que pertenezca una serie radiofónica (ciencia-ficción, policíaca, comedia, drama...) puede resultar más o menos frecuente la presencia de efectos sonoros que designen una realidad reconocible para el oyente o de sonidos que se adentran en el terreno de lo irreal. Este último aspecto propicia la experimentación sonora, en la que la tecnología y la imaginación juegan un papel importante.

Del mismo modo, la temática de la serie condiciona el perfil de los efectos empleados, no solo en su vertiente 'real' o 'imaginaria', sino también en lo referente a su vinculación con el tipo de escenarios, acciones o patrones narrativos del propio género. Así, en una serie policíaca puede resultar frecuente la presencia de disparos, ambientes relacionados con comisarías, persecuciones, sirenas de policía, etc.; ${ }^{2}$ en una serie de misterio pueden aparecer sonidos como truenos, campanadas, pasos sigilosos...; mientras que en una comedia de situación es habitual el empleo de recursos sonoros vinculados a espacios interiores y a la vida de los personajes. Ello no impide que una serie de carácter policíaco, por ejemplo, pueda contener a su vez efectos de carácter general (ambiente de calle, sonido de tren...), como los aparecidos en otros formatos. Del mismo modo, determinados géneros temáticos son más proclives a la dimensión descriptiva y objetiva de los efectos, mientras que en otros cobra especial relevancia su vertiente expresiva y subjetiva, cuestión que se aprecia también en el empleo de las músicas.

En este contexto, resultan de especial interés las funciones que los efectos sonoros desempeñan en el transcurso de la historia, cuestión clave en la selección de estos. Para ello tomaremos como referencia la tipología y conceptos propuestos por Balsebre (2007, pp. 126-133) y Gutiérrez y Perona (2002, pp. 60-61): ${ }^{3}$

- Función ambiental o descriptiva (o descriptivo-ambiental): el efecto restituye la realidad objetiva, denotándola semánticamente, forma parte del ambiente en el que se desarrolla la acción y tiene carácter naturalista. Existe congruencia entre los contornos sonoros del objeto o acción representados y la imagen que expresan.

- Función expresiva (o descriptivo-expresiva): el efecto refuerza los sentimientos, los estados de ánimo de los protagonistas. El efecto connota la descripción realista suscitando una relación afectiva. Se basa en los distintos códigos particulares de significación simbólica.

2 En relación con la ambientación sonora de las series policíacas de los años cuarenta-sesenta se recomienda consultar Barea (1994, pp. 155-157).

3 Resulta de interés a su vez la clasificación y ejemplos aportados por Kaplún (1978, pp. 175-178). 


\section{DISERTACIONES}

ESTUDIOS

El papel del sonido en la comunicación: contribución, funciones y efectos

ISSN: $1856-9536$

Doi: http://dx.doi.org/10.12804/revistas.urosario.edu.co/disertaciones/a.6403

Volumen 12, Número 2 / Julio-diciembre 2019

Versión PDF para imprimir desde

http://revistas.urosario.edu.co/index.php/disertaciones

- Función narrativa: los efectos que se ubican en esta modalidad pueden desempeñar a su vez diversos tipos de funciones: marcar la transición espacio/temporal entre una secuencia y otra (actúan de nexo entre secuencias), reconstruir una acción que no precisa ni de palabra ni de música, representar a un personaje o resaltar una característica importante de él.

- Función ornamental: esta función no define un mensaje semántico, sino estético. Es un efecto sonoro subsidiario, accesorio de la palabra radiofónica, que puede reforzar el ambiente en el que transcurre la acción. No es imprescindible en la historia, ni necesario para otorgar verosimilitud a la misma. Acentúa el valor estético del mensaje.

En un elevado porcentaje de series radiofónicas, la función de los efectos sonoros que predomina es la ambiental o descriptiva, aspecto comprensible al recurrir los autores de forma mayoritaria a sonidos que tienen un referente directo en el mundo real, lo que otorga, en gran medida, verosimilitud a las escenas. En esta función podemos aludir a efectos como los que ejemplifican Gutiérrez y Perona (2002): sonido de teléfono, pasos, el viento que acentúa la frialdad del ambiente en invierno...

No obstante, junto a la vertiente descriptivo-ambiental, en las series también se emplea de forma habitual la dimensión narrativa de los efectos. Actúan frecuentemente como nexo o transición espacio-temporal entre escenas: concatenación de efectos que simbolizan el paso de un escenario interior (ambiente de restaurante) a uno exterior (ruido de tráfico), el paso del tiempo (tic-tac reloj), etc. Este tipo de transiciones suelen estar reforzadas y complementadas por otros elementos del lenguaje radiofónico como la música (recurso frecuente) o la palabra (los propios diálogos pueden anticipar el cierre de una escena o el paso a otro escenario, también favorece la transición la entrada y salida de personajes). Como se ha podido observar en la tipología citada, los efectos sonoros en su dimensión narrativa pueden cumplir también la función de identificar a un personaje (ej.: a través de sus pasos) o de representar una acción sin la necesidad de ser complementada con la palabra (explosión, abrir una puerta...) —no nos detendremos en la función ornamental-.

Es una práctica habitual en las series que el guionista seleccione efectos sonoros que desempeñen más de una función simultáneamente, como podremos comprobar en los resultados de este estudio. Por ejemplo, en un episodio en el que un trueno ha desencadenado el inicio de una tormenta, el sonido describe un efecto ambiental de la historia, pero puede cumplir a su vez una función expresiva, al generar un ambiente proclive al misterio (miedo, incertidumbre...), y desempeñar una función narrativa, si se ubica como nexo entre escenas. La dimensión subjetiva en el empleo de los efectos sonoros pone de relieve el poder evocador del sonido (Chion, 1999).

Además, se podría hacer alusión a la vinculación que pueden presentar los efectos con los escenarios fijos o episódicos de una serie y a la reiteración de un mismo tipo de efectos en los episodios de un seriado.

Por otra parte, en relación con el guion técnico de cada episodio, el autor al escribir la historia otorga a los efectos sonoros distintos niveles de protagonismo y funciones: primer plano, plano de fondo, ${ }^{4}$ sonido único representado de forma autónoma, efectos superpuestos, concatenación de sonidos, etc. Del mismo modo, el guionista puede introducir los efectos con un propósito de redundancia o de complemento, respecto a otros elementos del lenguaje radiofónico presentes en el relato (Merayo \& Pérez, 2001), o bien que sea el resto de los elementos que rodean al efecto los que

4 Según Ortiz y Volpini, los efectos "conforman, principalmente, el fondo, el ACOMPAÑAmiento, el AmBiente donde la acción se desarrolla” (1998, p. 50). 


\section{DISERTACIONES}

ESTUDIOS

El papel del sonido en la comunicación: contribución, funciones y efectos

ISSN: 1856-9536

Doi: http://dx.doi.org/10.12804/revistas.urosario.edu.co/disertaciones/a.6403

Volumen 12, Número 2 / Julio-diciembre 2019

Versión PDF para imprimir desde

http://revistas.urosario.edu.co/index.php/disertaciones

concedan un protagonismo especial a dicho sonido. Por lo tanto, es importante la elección, descripción y ubicación de los efectos sonoros de cara al montaje posterior o a la propia recreación en directo.

El perfil de estos efectos ha ido evolucionando con el tiempo y también su modo de producción. Los especialistas en efectos sonoros de las emisoras, cuyas manos "estimulaban con virtuosismo la imaginación del oyente" (Afuera, 2011), ${ }^{5}$ han dado paso a laboratorios sonoros cada vez más sofisticados (Soengas, 2010). Ello no impide que sigamos indagando en los guiones que han formado parte de nuestra historia de la radio. Adentrémonos en Taxi Key.

\section{La serie radiofónica Taxi Key}

El sábado 2 de octubre de 1948 a las 22.30 h nace Taxi Key en las ondas de Radio Barcelona. Creada por Luis G. de Blain, esta serie policíaca, ubicada en el programa-concurso ¿Es usted buen detective?, se erigió como ficción clave entre la audiencia barcelonesa. Su particular formato, en el que se entremezclaba el suspense con el humor y se concedía un lugar prioritario a la participación de los oyentes, los enigmas episódicos y las aventuras del carismático Taxi Key, concedieron a Taxi Key el privilegio de convertirse en una serie radiofónica de referencia que se mantuvo en antena durante casi 20 años.

Cada emisión del programa-concurso se difundía semanalmente ${ }^{6}$ y constaba de una duración de 30 minutos. Se mantenían constantes fundamentalmente dos elementos. En primer lugar, el planteamiento de un enigma vinculado a la comisión de un hecho delictivo, en el que el protagonista de la serie, el abogado, taxista y detective/investigador privado norteamericano Taxi Key, y/o sus acompañantes, se encontraban involucrados de algún modo. En segundo lugar, la participación de los oyentes que debían averiguar quién era el culpable del caso, demostrando su faceta de detectives. Una vez que se habían aportado las pistas suficientes en cada episodio, y que el perspicaz Taxi Key disponía de la información necesaria para descubrir la identidad del criminal, se interrumpía la emisión de la historia con un 'golpe de gong' y se retomaba el programa-concurso, dando paso al 'interrogatorio', tal y como revelan los guiones radiofónicos de la serie. Finalmente, el protagonista aportaba las claves del enigma y resolvía el misterio (guiones de la serie Taxi Key \& Balsebre, 2002).

En relación con los efectos de sonido, como relata Cortés (2010), los propios actores contribuían en la reproducción de la ambientación sonora del episodio en determinados efectos. Destaca Cortés que en Taxi Key había la famosa puerta-ventana, que era un artilugio de madera que constaba de diferentes partes y servía para realizar distintos efectos sonoros. ${ }^{7}$ Junto a este instrumento disponían de otros artilugios. Sin embargo, Cortés puntualiza que en Taxi Key eran los mínimos, pues ya era "un programa de concepción más moderna", en palabras del actor. "El Taxi Key era un programa moderno, coches que llegaban, que tenían efectos, efectos que ya no hacíamos, a los que se unían otros que a nosotros nos marcaban: Cortés timbre, ring. [...] Cuando llegabas lo tenías marcado y lo hacías tú. Por ejemplo, había un timbre al lado para poder hacerlo. Había timbres de ring y otros de mecc, teléfono... Esto lo hacíamos los actores de Radio Barcelona" (S. Cortés, entrevista personal, julio de 2010). En este

5 Se recomienda escuchar El armario de los ruidos - artilugio “lleno de aldabas, cajones, puertas y cerrojos..."(Afuera, 2011): Recuperado de http://cadenaser.com/emisora/2011/06/29/audios/1309303039_660215.html

6 En algunos momentos puntuales de la serie se llegaron a emitir más de dos episodios en una misma semana.

7 Recordemos 'el armario de los ruidos' citado anteriormente. 


\section{DISERTACIONES}

ESTUDIOS

El papel del sonido en la comunicación: contribución, funciones y efectos

ISSN: $1856-9536$

Doi: http://dx.doi.org/10.12804/revistas.urosario.edu.co/disertaciones/a.6403

Volumen 12, Número 2 / Julio-diciembre 2019

Versión PDF para imprimir desde

http://revistas.urosario.edu.co/index.php/disertaciones

contexto en determinados guiones de la serie aparecen especificaciones tales como Trueno Fuerte (Bombo), Disparo Lejano (En Disco), Disco De Pasos... Descubramos más cuestiones sobre la ambientación acústica de Taxi Key en las páginas siguientes.

\section{Objetivos}

Como se ha puesto de manifiesto en páginas previas, en el presente artículo haremos referencia a uno de los elementos del lenguaje radiofónico que da forma a la expresión sonora de los episodios de la serie Taxi Key: los efectos sonoros. Se plantea como objetivo prioritario:

- Identificar y describir qué funciones de los efectos sonoros prevalecen en los guiones radiofónicos de la serie Taxi Key, así como su vinculación con el género policíaco y la ambientación de misterio.

Del mismo modo, se persiguen a su vez los siguientes objetivos:

- Establecer si existe evolución en cuanto al número de efectos empleados en función de las diversas etapas del seriado.

- Determinar cuáles son los efectos de sonido más frecuentes en los capítulos analizados.

\section{Metodología}

El que se presenta a continuación es un estudio de carácter exploratorio en el que se plantean análisis descriptivos e inferenciales. Se han aplicado tanto técnicas cuantitativas como cualitativas, al ser ambas idóneas para el objeto de estudio que nos ocupa (Casetti \& Di Chio, 1999; Igartua, 2006; García \& Berganza, 2005; Hernández Sampieri, Fernández Collado \& Baptista Lucio, 2010).

El estudio cuantitativo se realiza con el propósito de poder determinar el grado de prevalencia de cada elemento y su evolución en las distintas etapas de la serie. El análisis cualitativo parte, por un lado, de los datos obtenidos a través del análisis estadístico, pues estos actúan como punto de referencia de la descripción e interpretación. Sin embargo, en el estudio cualitativo se han establecido a su vez categorías específicas y se han recopilado datos no numéricos, como los referentes a la descripción de los efectos sonoros.

El análisis que se plantea a continuación forma parte de una investigación más amplia dedicada al estudio de la serie radiofónica Taxi Key.

\section{Muestra de estudio}

Para la elaboración de este estudio, se han seleccionado como unidades de análisis los guiones radiofónicos originales de la serie policiaca Taxi Key. La muestra está constituida por 40 guiones, seleccionados a partir de criterios cronológicos y narrativos. Como se ha especificado anteriormente, los resultados que se incluyen a continuación forman parte de una investigación más amplia, por lo tanto, el perfil de la muestra se adscribe a esta circunstancia.

En cuanto a los criterios de selección muestral, y en relación con el criterio cronológico, en la muestra se encuentran representados todos los años de emisión de la serie, excepto aquellos en los que se interrumpe la transmisión de Taxi Key (1959-1961). 
Se han definido tres épocas de estudio: época I. 1948-1950, años iniciales de la serie (el $30 \%$ de la muestra); época II. 1951 a 1958 (el $40 \%$ de la muestra); época III. Desde 1962 hasta la finalización de la serie, en 1967 (30\%). Con esta distribución se puede afirmar que las tres épocas están homogéneamente representadas con $\mathrm{p}>0,05$ $\left(\mathrm{Chi}^{2}=0,800 ; 2 \mathrm{gl} ; \mathrm{p}=0,670\right)$.

En lo relativo al método de selección de la muestra, y debido a las características de nuestro estudio, nos decantamos por una muestra de carácter no probabilístico, puesto que se persigue inferir, con carácter exploratorio, tendencias de la muestra seleccionada.

\section{Instrumento de análisis}

La última parte relacionada con el ámbito metodológico del estudio es la dedicada al instrumento de análisis. Así, se ha diseñado un instrumento que permitiera registrar la información cuantitativa y cualitativa de la investigación.

Para ello, se han integrado en una misma herramienta elementos de análisis de carácter cuantitativo y cualitativo, para que de ese modo el procedimiento de recogida y análisis de datos correspondientes a cada guion se pudiera efectuar de forma simultánea y conjunta. El análisis estadístico de los datos ha requerido la codificación a través del programa IBM SPSS Statistics 20.

Se incluyen, a continuación, las distintas dimensiones de análisis (ver tabla 1):

Tabla 1. Análisis de los efectos sonoros

\begin{tabular}{|c|c|c|c|c|}
\hline \multicolumn{5}{|c|}{ Efectos sonoros } \\
\hline \multicolumn{5}{|l|}{ Número total } \\
\hline \multirow{3}{*}{ Funciones } & Ambiental - descriptiva & \multicolumn{2}{|c|}{ Registro numérico (0-3) } & Descripción/datos \\
\hline & Expresiva & \multicolumn{2}{|c|}{ Registro numérico (0-3) } & \\
\hline & Narrativa & \multicolumn{2}{|c|}{ Registro numérico (0-3) } & \\
\hline \multirow{14}{*}{$\begin{array}{c}\text { Efectos sonoros } \\
\text { habituales }\end{array}$} & \multirow{2}{*}{\multicolumn{2}{|c|}{ Motor auto }} & No $(0)$ & Observaciones \\
\hline & & & Sí (1) & \\
\hline & \multirow{2}{*}{\multicolumn{2}{|c|}{ Frenazo }} & No $(0)$ & \\
\hline & & & Sí (1) & \\
\hline & \multirow{2}{*}{\multicolumn{2}{|c|}{ Puerta }} & No $(0)$ & \\
\hline & & & Sí (1) & \\
\hline & \multirow{2}{*}{\multicolumn{2}{|c|}{ Pasos }} & No $(0)$ & \\
\hline & & & Sí (1) & \\
\hline & \multirow{2}{*}{\multicolumn{2}{|c|}{ Disparo }} & No $(0)$ & \\
\hline & & & Sí (1) & \\
\hline & \multirow{2}{*}{\multicolumn{2}{|c|}{ Trueno }} & No $(0)$ & \\
\hline & & & Sí (1) & \\
\hline & \multirow{2}{*}{\multicolumn{2}{|c|}{ Reloj (incluye reloj-campanada) }} & No $(0)$ & \\
\hline & & & Sí (1) & \\
\hline Otros datos & \multicolumn{2}{|c|}{ Descripción de efectos sonoros } & \multicolumn{2}{|c|}{$\begin{array}{l}\text { Observaciones (especificaciones de efectos, género policíaco/ } \\
\text { ambientación de misterio, diegéticos/extradiegéticos...). }\end{array}$} \\
\hline
\end{tabular}

Fuente: elaboración de la autora. 


\section{DISERTACIONES}

ESTUDIOS

\section{Efectos sonoros}

1.1. Número total: se han registrado solamente aquellos efectos que identifiquen diferentes tipos de referentes (sonido de campana, trueno, pasos, etc.), sin contabilizar sus diversas variantes (ej.: no se ha contabilizado el efecto puerta como siete efectos en el caso de que aparezca en siete ocasiones, a pesar de que se materialice como puerta que se abre, puerta que se cierra, chirriar de puerta, etc.). Al formar parte de una investigación más extensa no se ha seleccionado como objeto de estudio dicho aspecto. Por lo tanto, el número de modalidades de efecto no se corresponde con el número total de efectos que aparecen en un episodio (cifra superior), en el que se puede llegar a emplear incluso un mismo efecto en numerosas ocasiones en el transcurso del capítulo.

1.2. Funciones de los efectos sonoros: se ha tomado como referencia la tipología y definiciones especificadas en el epígrafe dedicado a los efectos sonoros en las series radiofónicas basada en: Balsebre (2007, pp. 126-133) y Gutiérrez y Perona (2002, pp. 60-61) -se ha prescindido de la función ornamental-:

- Ambiental o descriptiva

- Expresiva

- Narrativa

Las funciones de los efectos sonoros se han registrado a través de una variable de carácter ordinal que se materializará en el análisis de cada capítulo del siguiente modo:

$0=$ ausencia de la función

1 = función de mayor relevancia en el episodio, mayor porcentaje de presencia (10).

2 = segunda función en porcentaje de presencia o importancia en capítulo $\left(2^{\circ}\right)$.

3 = tercera función en porcentaje de presencia o importancia en capítulo (3०).

1.3. Efectos sonoros habituales: se establecieron tomando como referencia la lectura previa de guiones de Taxi Key.

\subsection{Otros datos.}

A continuación se incluyen los resultados del estudio.

\section{Resultados}

En el análisis de las características narrativas de la serie Taxi Key, no podemos obviar el estudio de los efectos sonoros empleados por el guionista, pues debemos considerarlos ingredientes fundamentales en la representación acústica de cada relato episódico. Resulta de interés subrayar que en determinados capítulos la dimensión sonora de la historia se destaca ya en el propio título del episodio: "Un reloj suena en la casa vacía”, "El organista fantasma”, "El tañido de la muerte", "La aventura del sonido que no se oyó"...

En las páginas siguientes detallaremos las dimensiones de análisis indicadas anteriormente.

\section{Funciones de los efectos sonoros}

Si nos detenemos, en primer lugar, en las funciones de los efectos sonoros en la serie Taxi Key, los resultados revelan que, como era de prever, la función que aparece en todos los capítulos analizados es la descriptivo-ambiental. En el $100 \%$ de los episodios, el guionista emplea efectos que cumplen la función de restituir la realidad objetiva. Existe, por lo tanto, una correspondencia directa entre la realidad u objeto representado y el recurso sonoro a través del 
que se expresa en el guion. Prevalece el carácter diegético de los efectos sonoros, puesto que en casi la totalidad de las ocasiones forman parte de la historia narrada. El evocar sonidos que existen en la realidad facilita al oyente la asociación de cada efecto con su referente.

\section{Efectos sonoros. Función descriptivo-ambiental}

MÚSICA DE FONDO = ENCADENA CON TIMBRE INSISTENTE

TAXI: ¡Ya va, ya va!... ¿Quién demonios puede ser a estas horas de la madrugada?

TIMBRE

Guion: 6 de noviembre de 1948, 22.30 h. Episodio: "Se busca medio millón de dólares".

En este contexto, aparecen tanto sonidos que recrean objetos, mobiliario... (teléfono, puerta...) como efectos que representan realidades más amplias (ej.: escenario exterior calle - ambientado a través de ruido de tráfico, canto de grillos en la noche - escenario exterior campo).

\section{Efectos sonoros. Función ambiental}

TAXI: La acompañaré... ¡Vamos!

STELLA: Mire, señor Key, le agradecería que no me acompañase. Es un poco tarde ya y voy a tomar un taxi...

Guion: 24 de marzo de 1951, 21.05 h. Episodio: “Crimen en la biblioteca pública”.

Los sonidos que cumplen la función descriptivo-ambiental juegan un papel fundamental en los guiones al otorgar verosimilitud a la escena representada y erigirse como recurso prioritario en la recreación de los escenarios en los que se desarrolla la historia.

Junto a la función ambiental y descriptiva, que está presente en la totalidad de los guiones y ha sido registrada como la más frecuente en todos ellos, la función narrativa aparece en segundo lugar, en el $75 \%$ de los episodios. Destaca en su vertiente de nexo espacio-temporal entre escenas.

\section{Efectos sonoros. Función narrativa. Transición espacial y temporal}

TAXI.- Mira, lo único que puedo decirte es que tendré mi dinero antes de llegar a Nueva York.

GLOSS.- ¿Sí?... Bueno, pues yo te acompaño... para mayor seguridad. ¡Andando! SONIDO. RESTAURANTE FUNDE Y ENCADENA CON RUIDO DE TREN EN MARCHA. A FONDO.

TAXI.- Lo primero que hice, después de instalarme en mi compartimento, fue iniciar una búsqueda sistemática de Larsen a todo lo largo del tren.

Guion: 19 de noviembre de 1964, 20.00 h. Episodio: “La aventura del hombre que huía”. 


\title{
DISERTACIONES
}

ESTUDIOS

El papel del sonido en la comunicación: contribución, funciones y efectos

ISSN: 1856-9536

Doi: http://dx.doi.org/10.12804/revistas.urosario.edu.co/disertaciones/a.6403

Volumen 12, Número 2 / Julio-diciembre 2019

Versión PDF para imprimir desde

http://revistas.urosario.edu.co/index.php/disertaciones

Los resultados revelan que los efectos sonoros aparecen como recurso que favorece las transiciones temporales un $48,6 \%$ de las veces (17 de 35 episodios). ${ }^{8} \mathrm{Al}$ comparar entre épocas, no se perciben diferencias estadísticamente significativas con $p>0,05$. En este contexto, en la serie se utilizan diversos tipos de efectos y estrategias para materializar las elipsis funcionales: ${ }^{9}$ efectos sonoros diegéticos o extradiegéticos que evidencian el paso del tiempo -el tic-tac de un reloj, el sonido de un metrónomo, las campanadas...-y a menudo aparecen acompañados de otros recursos -intervención de alguno de los personajes que redunda en la información aportada por el efecto o proporciona nuevos datos que permiten clarificar determinados aspectos...-, elipsis construidas a través del encadenado o fundido de dos o más efectos sonoros, que, junto a la transición temporal, facilitan la transición espacial...

\section{Efectos sonoros. Función narrativa. Transición entre escenas}

TAXI: (FURIOSO Y ENTRE DIENTES) ¡Vaya, y ahora me dejan aquí, solo, mirando las musarañas y con el taxi inactivo......, pues sí que voy a hacer esta noche un bonito negocio (LA VOZ SE EXTINGUE). La gasolina para regresar al centro de Hollywood me va a costar más de...

\author{
LA VOZ ENCADENA CON TIC-TAC RELOJ \\ UN RELOJ DA EL CUARTO (DISCO) \\ SIGUE TIC-TAC, QUE ENCADENA CON VOZ...
}

TAXI: ¡Y ya va un cuarto de hora que me tienen aquí como un bobo... y nadie aparece por ningún lado y toda la casa está silenciosa como una tumba!... Se diría que todo el mundo se ha muerto, ¡caramba! BOLTON Y FAY LLEGAN HABLANDO ENTRE SÍ INENTILIGIBLEMENTE.

Guion: 12 de febrero de 1949, 23.10 h. Episodio: "Taxi Key, otra vez taxista”.

No obstante, los efectos registrados en esta categoría (función narrativa) se emplean también para reconstruir acciones que no precisan ni de palabra ni de música. Del mismo modo, pero en menor medida, se han identificado efectos empleados para identificar un personaje o resaltar una característica importante de él, por ejemplo, los pasos del asesino.

Por su parte, en el 42,5\% de los episodios la función expresiva ocupa la tercera posición, debido a la frecuencia con la que se emplean efectos ligados a las otras dos funciones. Ello no supone que sea menos significativa, puesto que resulta indispensable en la recreación de la sensación de suspense, intriga y misterio, al aportar una dimensión connotativa de los efectos sonoros. En algunos casos esta función llega a alcanzar la segunda posición en grado de relevancia en el capítulo, por delante de la narrativa. Sin embargo, la función ambiental siempre se encuentra en primer lugar, puesto que, por lo general, todos los efectos que aparecen en los episodios son diegéticos y restituyen denotativamente la realidad.

8 No se encuentran incluidos los capítulos en los que se ha registrado diégesis pura (= el tiempo de la historia desarrollada a lo largo de un capítulo es idéntico al tiempo de su emisión).

9 Elipsis funcional: se concebirá como funcional al tipo de elipsis en la que se omite una parte insustancial del relato - por ejemplo, cuando se produce un avance en el tiempo en el que no sucede ninguna situación relevante para el oyente- (Rodero, 2005, p. 245). 
La función expresiva de los efectos sonoros aparece de forma más marcada en unos episodios que en otros. De hecho, en algunos de los capítulos alcanza un elevado protagonismo, mientras que en otros su presencia es muy limitada. Desempeña un papel prioritario el efecto trueno y otros clásicos en el género vinculados a la noche, la tormenta, etc., como viento lúgubre, lluvia, campanadas, aldabonazos a la puerta durante la noche... Debido a las propias características de esta función, adquiere especial relevancia el lugar en que se encuentre ubicado el efecto (después de un diálogo en el que se intuye que algo intrigante va a suceder, sonido inesperado que se introduce para generar sorpresa en los personajes y oyentes, etc.).

\section{Efectos sonoros. Función expresiva (+ función descriptivo-ambiental + función narrativa)}

\section{TRUENO}

BASIL: Llamaré a la policía, es lo más prudente (RUIDO MARCADOR TELÉFONO)... Vaya, menos mal que la tormenta no ha averiado también la línea telefónica.... Oiga, ¿la Jefatura de Policía de Bay City?... Aquí la mansión Ferris... Envíen enseguida a un par de agentes. Estamos aislados a causa de la tormenta y un loco homicida se ha introducido en la casa. ¡Dense prisa, es urgente!... Muy bien.

TÍA: ¿Qué te han dicho?

BASIL: Que enseguida vendrán. Ahora es cuestión de armarse de paciencia y esperar. Aconsejo que permanezcamos todos reunidos con objeto de no dar ocasión de repetir el atentado a ese maldito loco.

TRUENO = ENCADENA CON MÚSICA DE FONDO, QUE FUNDE EN TIC-TAC METRÓNOMO, QUE ENCADENA CON TRUENO

Guion: 2 de octubre de 1948, 22.30 h. Episodio: "Taxi Key interviene”.

Como se puede observar en algunos de los ejemplos anteriores, los efectos empleados pueden desempeñar más de una función simultáneamente (ej.: descriptivo-ambiental + narrativa). Este procedimiento de combinación de funciones a partir de unos mismos efectos resulta ser una estrategia frecuente en la serie. Incluso, los sonidos registran en determinadas escenas una triple función (descriptivo-ambiental + expresiva + narrativa). Por ejemplo, en el fragmento anterior el trueno es un efecto diegético que cumple una función ambiental y descriptiva (noche de tormenta), favorece la transición temporal entre escenas, junto con la música y el metrónomo, y desempeña una función expresiva al intensificar el ambiente de misterio y suspense en unos instantes de tensión. Detallamos otro ejemplo a continuación. 


\section{DISERTACIONES}

El papel del sonido en la comunicación: contribución, funciones y efectos

ISSN: $1856-9536$

Doi: http://dx.doi.org/10.12804/revistas.urosario.edu.co/disertaciones/a.6403

Volumen 12, Número 2 / Julio-diciembre 2019

Versión PDF para imprimir desde

http://revistas.urosario.edu.co/index.php/disertaciones

\section{Efectos sonoros. Función expresiva + función descriptivo-ambiental + función narrativa}

\section{TRUENO FUERTE}

GER. Y DANNY: ¡A-a-ay!

BAXTER: Bueno, no se asusten, ha sido un trueno, nada más que un trueno. Aquí llega Hildegarda...... Con el permiso de ustedes. Buenas noches.

GER., DANNYY TAXI: ¡Buenas noches!

DANNY: (VOZ QUE SE EXTINGUE) ¡O-ojalá sea bue-buena!

MÚSICA DE FONDO = SE APIANA

SUENA RELOJ CARRILLÓN DANDO LAS DOCE

GOLPES CON LOS NUDILLOS EN PUERTA

GER.: (en voz baja) ¡Taxi!... ¡Taxi Key!

CHIRRIDO DE PUERTA AL ABRIRSE

Guion: 18 de diciembre de 1948, 22.30 h. Episodio: "La casa del terror”.

En el siguiente fragmento también se puede observar una combinación de funciones, entre las que se encuentran la descriptivo-ambiental y narrativa (explosión, detonaciones...) y la expresiva (viento lúgubre).

\section{Funciones de los efectos sonoros}

\section{SONIDO: VIENTO LÚGUBRE}

NORAH- (NARRA) Pasaron lentamente los minutos hasta que, de pronto, todas las luces de la casa se apagaron y....

SONIDO: LEJOS EXPLOSIÓN

GLOSS.- ¿Qué ha sido esa explosión?

NORAH- No lo sé. Ha sonado en la parte baja de la isla.

GLOSS.- Por la ventana no se ve nada.

NORAH- Nada, ni siquiera las luces del pueblo. ¡Eso significa que toda la isla se ha quedado a oscuras!

(...)

SONIDO: LEJOS TRES DETONACIONES

HEND.- ¡Dios mío, son detonaciones!

Guion: 10 de agosto de 1967, 21.30 h. Episodio: "La aventura de la isla en peligro".

\section{Número de efectos sonoros}

Junto a la identificación de funciones, también es preciso detenerse en la diversidad de efectos sonoros empleados. Los datos revelan que el número de efectos por episodio, que representan una determinada modalidad de referente (puerta, campanadas, viento...), independientemente de los matices que manifieste cada efecto, se encuentra en un rango de valores entre 1 efecto (2,5\%, 1 vez) y 21 (2,5\%, 1 vez). Los resultados revelan que la media se sitúa en 


\section{DISERTACIONES}

ESTUDIOS

El papel del sonido en la comunicación: contribución, funciones y efectos

ISSN: 1856-9536

Doi: http://dx.doi.org/10.12804/revistas.urosario.edu.co/disertaciones/a.6403

Volumen 12, Número 2 / Julio-diciembre 2019

Versión PDF para imprimir desde

http://revistas.urosario.edu.co/index.php/disertaciones

8,65 \pm d.t. 4,01 (IC 95\%: 7,37-9,93) y el caso más frecuente corresponde a la presencia de 8 clases de efectos, cifra que aparece en un $17,5 \%$ de los episodios.

Los guiones de la muestra evidencian cómo en los primeros años de la serie existe una gama más variada de efectos sonoros y una mayor presencia de estos que en el resto. Así lo demuestra el segundo episodio, titulado "Un reloj suena en la casa vacía”. De los estudiados, este es el capítulo que registra una mayor diversidad de efectos sonoros. Así, al comparar por épocas (ver tabla 2), se han observado diferencias claramente significativas con $p<0,001(F=11,528 ; 2$ y $37 \mathrm{gl} ; \mathrm{p}=0,000)$. Dichas diferencias se establecen entre la primera época y las otras dos, pero no entre ellas, al comparar los pares de medias con los tests múltiples HSD y DMs. Por lo tanto, resulta necesario subrayar que la utilización de efectos sonoros es significativamente mayor en la primera etapa respecto a las otras dos. ${ }^{10}$ Al ser esta la etapa que supone el punto de partida de la serie, puede llegar a concebirse como un período inicial, en el que, de la misma manera que personajes y tramas van evolucionando y tienden hacia su consolidación, el empleo de los efectos sonoros, en cuanto a tipología y uso, puede haber experimentado un proceso similar.

Tabla 2. Número de efectos sonoros

Test de diferencia de medias, comparación por época

\begin{tabular}{|c|c|c|c|c|c|c|c|c|}
\hline \multirow{2}{*}{\multicolumn{2}{|c|}{ Factores }} & \multirow{3}{*}{$\begin{array}{l}N \\
40\end{array}$} & \multirow{3}{*}{$\begin{array}{c}\text { Media } \\
8,65\end{array}$} & \multirow{3}{*}{$\begin{array}{l}\text { D. T. } \\
4,01\end{array}$} & \multirow{3}{*}{$\begin{array}{l}\text { Test post hoc DMS y HSD } \\
\text { Pares significativos }\end{array}$} & \multicolumn{3}{|c|}{ Anova de 1 factor } \\
\hline & & & & & & \multirow{2}{*}{ Valor F } & \multirow{2}{*}{ gl } & \multirow{2}{*}{ p } \\
\hline \multirow{4}{*}{$\begin{array}{l}\text { Número de } \\
\text { efectos sonoros } \\
\text { utilizados por } \\
\text { capítulo }\end{array}$} & Muestra total & & & & & & & \\
\hline & Época I & 12 & $12,25^{\mathrm{A}}$ & 4,27 & \multirow{3}{*}{$\begin{array}{l}(A ; B) p=, 001^{\star \star} \\
(A ; C) p=, 000^{\star \star}\end{array}$} & \multirow{3}{*}{11,528} & \multirow{3}{*}{2 у 37} & \multirow{3}{*}{, $000^{\star \star}$} \\
\hline & Época II & 16 & $7,81^{\mathrm{B}}$ & 3,17 & & & & \\
\hline & Época III & 12 & $6,17^{c}$ & 1,80 & & & & \\
\hline
\end{tabular}

\section{Tipo de efectos sonoros}

En cuanto al tipo de efectos sonoros empleados en la serie Taxi Key, los resultados del estudio demuestran que en los episodios objeto de análisis el guionista recurre a efectos sonoros de carácter general (timbre, teléfono, motor de auto, portazo, ruido de tráfico...), a sonidos que se hallan vinculados a los escenarios episódicos (campanadas de niebla, chapoteo de agua, para representar un puerto/muelle, rugidos de tigres, para identificar el circo, croar de ranas y canto de pájaros, para ambientar un parque con un estanque...), pertenecientes tanto a espacios exteriores como interiores, y a efectos específicos del género policíaco y la ambientación de misterio (trueno, campanadas lúgubres, disparo...). Además, en los guiones suele aparecer detallado únicamente el nombre del efecto sonoro, sin embargo, en algunos de ellos se especifica también la procedencia de la fuente sonora: Disparo Lejano (En Disco),

10 En algún guion concreto llama la atención la escasez de recursos sonoros utilizados en la ambientación de determinadas escenas para identificar los espacios y la transición entre escenarios, ya que no suele ser lo habitual. 
Disco Disparos: Tres Disparos tal como salen en El Disco, Trueno Fuerte (Bombo), Disco de Pasos que se unen a los de GLossop, etc.

Así mismo, el propio instrumento recogía ya un listado de efectos, de los que se pretendía examinar la frecuencia con la que aparecían en los diversos episodios. De estos efectos sonoros, que se habían tipificado como frecuentes, el estudio proporciona los siguientes resultados:

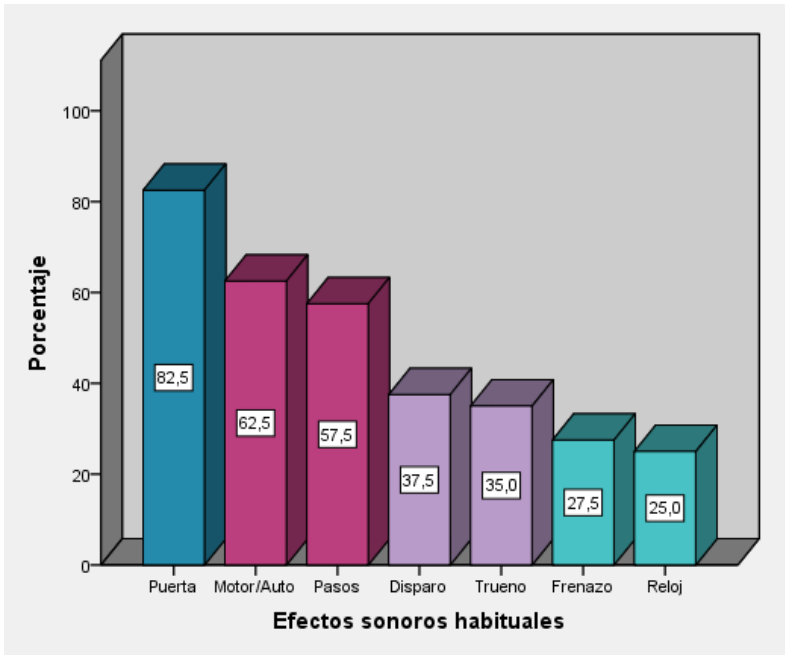

Figura 1. Frecuencia de efectos sonoros habituales

Fuente: elaborada por la autora mediante IBM SPSS Statistics 20.

Tabla 3. Efectos sonoros habituales. Comparación por época

\begin{tabular}{|c|c|c|c|c|c|}
\hline \multirow{2}{*}{ Variable } & \multicolumn{2}{|c|}{ Descriptivos } & \multicolumn{3}{|c|}{ Test de contraste } \\
\hline & Sí & No & Valor & gl & $\mathbf{p}$ \\
\hline Motor auto $(\mathrm{N}=40)$ & $62,5 \%(25)$ & $37,5 \%(15)$ & $\mathrm{Chi}^{2}=2,500$ & 1 &, $114^{\mathrm{NS}}$ \\
\hline $\begin{array}{l}\text { Época I }(n=12) \\
\text { Época II }(n=16) \\
\text { Época III }(n=12)\end{array}$ & $\begin{array}{c}83,3 \%(10) \\
56,2 \%(9) \\
50,0 \%(6)\end{array}$ & $\begin{array}{l}16,7 \%(2) \\
43,8 \%(7) \\
50,0 \%(6)\end{array}$ & $\mathrm{Chi}^{2}=3,546$ & 2 &, $170^{\mathrm{NS}}$ \\
\hline Frenazo $(\mathrm{N}=40)$ & $27,5 \%(11)$ & $72,5 \%(29)$ & $\mathrm{Chi}^{2}=8,100$ & 1 &, $004^{\star \star}$ \\
\hline $\begin{array}{l}\text { Época I }(n=12) \\
\text { Época II }(n=16) \\
\text { Época III }(n=12)\end{array}$ & $\begin{array}{c}33,3 \%(4) \\
37,5 \%(6) \\
8,3 \%(1)\end{array}$ & $\begin{array}{c}66,7 \%(8) \\
62,5 \%(10) \\
91,7 \%(11)\end{array}$ & $\mathrm{Chi}^{2}=3,723$ & 2 &, $155^{\mathrm{NS}}$ \\
\hline Puerta $(N=40)$ & $82,5 \%(33)$ & $17,5 \%(7)$ & $\mathrm{Chi}^{2}=16,900$ & 1 &, $000^{* *}$ \\
\hline $\begin{array}{l}\text { Época I }(n=12) \\
\text { Época II }(n=16) \\
\text { Época III }(n=12)\end{array}$ & $\begin{array}{c}91,7 \%(11) \\
87,5 \%(14) \\
66,7 \%(8)\end{array}$ & $\begin{array}{c}8,3 \%(1) \\
12,5 \%(2) \\
33,3 \%(4)\end{array}$ & $\mathrm{Chi}^{2}=2,881$ & 2 & $237^{\mathrm{NS}}$ \\
\hline
\end{tabular}




\section{DISERTACIONES}

\section{ESTUDIOS}

El papel del sonido en la comunicación: contribución, funciones y efectos

ISSN: 1856-9536

Doi: http://dx.doi.org/10.12804/revistas.urosario.edu.co/disertaciones/a.6403

Volumen 12, Número 2 / Julio-diciembre 2019

Versión PDF para imprimir desde

http://revistas.urosario.edu.co/index.php/disertaciones

\begin{tabular}{|c|c|c|c|c|c|}
\hline \multirow{2}{*}{ Variable } & \multicolumn{2}{|c|}{ Descriptivos } & \multicolumn{3}{|c|}{ Test de contraste } \\
\hline & Sí & No & Valor & gl & $\mathbf{p}$ \\
\hline Pasos $(N=40)$ & $57,5 \%(23)$ & $42,5 \%(17)$ & $\mathrm{Chi}^{2}=0,900$ & 1 &, $343^{N S}$ \\
\hline $\begin{array}{l}\text { Época I }(n=12) \\
\text { Época II }(n=16) \\
\text { Época III }(n=12)\end{array}$ & $\begin{array}{l}100 \%(12) \\
50,0 \%(8) \\
25,0 \%(3)\end{array}$ & $\begin{array}{c}0 \%(-) \\
50,0 \%(8) \\
75,0 \%(9)\end{array}$ & $\mathrm{Chi}^{2}=14,425$ & 2 &, $000^{\star *}$ \\
\hline Disparo $(\mathrm{N}=40)$ & $37,5 \%(15)$ & $62,5 \%(25)$ & $\mathrm{Chi}^{2}=2,500$ & 1 &, $114^{\mathrm{NS}}$ \\
\hline $\begin{array}{l}\text { Época I }(n=12) \\
\text { Época II }(n=16) \\
\text { Época III }(n=12)\end{array}$ & $\begin{array}{l}33,3 \%(4) \\
50,0 \%(8) \\
25,0 \%(3)\end{array}$ & $\begin{array}{l}66,7 \%(8) \\
50,0 \%(8) \\
75,0 \%(9)\end{array}$ & Chi $^{2}=1,972$ & 2 &, $373^{\mathrm{NS}}$ \\
\hline Trueno $(\mathrm{N}=40)$ & $35,0 \%(14)$ & $65,0 \%(26)$ & $\mathrm{Chi}^{2}=3,600$ & 1 &, $058^{\mathrm{NS}}$ \\
\hline $\begin{array}{l}\text { Época I }(n=12) \\
\text { Época II }(n=16) \\
\text { Época III }(n=12)\end{array}$ & $\begin{array}{l}25,0 \%(3) \\
43,8 \%(7) \\
33,3 \%(4)\end{array}$ & $\begin{array}{l}75,0 \%(9) \\
56,2 \%(9) \\
66,7 \%(8)\end{array}$ & $\mathrm{Chi}^{2}=1,093$ & 2 &, $579^{\mathrm{NS}}$ \\
\hline Reloj (N = 40) & $25,0 \%(10)$ & $75,0 \%(30)$ & $\mathrm{Chi}^{2}=10,000$ & 1 &, $002^{\star *}$ \\
\hline $\begin{array}{l}\text { Época I }(n=12) \\
\text { Época II }(n=16) \\
\text { Época III }(n=12)\end{array}$ & $\begin{array}{c}66,7 \%(8) \\
12,5 \%(2) \\
0 \%(-)\end{array}$ & $\begin{array}{c}33,3 \%(4) \\
87,5 \%(14) \\
100 \%(12)\end{array}$ & $\mathrm{Chi}^{2}=17,654$ & 2 &, $000^{* *}$ \\
\hline
\end{tabular}

Como reflejan la figura 1 y la tabla 3, de los efectos sonoros registrados el sonido que más aparece es el de puerta, en sus diversas modalidades (efecto puerta, portazo, abrir puerta, cerrar puerta, chirrido puerta, portazo suave...), que está presente en el $82,5 \%$ de los episodios, por lo que alcanza la mayoría significativa con $p<0,001$ $\left(\mathrm{Chi}^{2}=16,900 ; 1 \mathrm{gl} ; \mathrm{p}=0,000\right)$.

En segundo lugar, el efecto motor de auto aparece en el 62,5\% de los guiones, sin que existan cambios significativos con $p>0,05$ entre las épocas, a pesar de que se pueda apreciar una mayor presencia en la primera etapa $(83,3 \%)$ respecto a las otras dos (en torno al $50 \%)$. En consecuencia, podemos aludir al protagonismo de este medio de transporte en la serie, bien sea identificando al taxi del personaje protagonista o a otro automóvil particular (de personaje principal, secundario o episódico) o de carácter profesional (coche de policía, taxi diferente al de Taxi Key...). Representando también esta misma realidad aparece el sonido de frenazo, que está presente en el 27,5\% de los capítulos, lo que supone minoría significativa con $\mathrm{p}<0,01\left(\mathrm{Chi}^{2}=8,100 ; 1 \mathrm{gl} ; \mathrm{p}=0,004\right)$.

Así mismo, el efecto pasos, en sus diversas modalidades, está presente en más de la mitad de los capítulos analizados (57,5\%). En este caso, aparece un claro cambio significativo entre las épocas con p <0,001 $\left(\mathrm{Chi}^{2}=\right.$ 14,$425 ; 2 \mathrm{gl} ; \mathrm{p}=0,000$ ), puesto que mientras que se encuentra representado en todos los episodios de la primera etapa, su presencia se reduce al $50 \%$ en la segunda época y al $25 \%$ en la tercera. El efecto pasos desempeña diferentes funciones entre las que destacan la expresiva, vinculada a las situaciones de misterio, y la narrativa, relacionada con la identificación de un determinado personaje (ver anexo). 


\section{DISERTACIONES}

\section{ESTUDIOS}

Por su parte, el efecto disparo aparece en el 37,5\% de los guiones. Además de por ser uno de los procedimientos habituales en el género policíaco, la presencia del efecto disparo/detonación cobra aún más valor en el medio radiofónico debido a la naturaleza sonora de este tipo de crimen. El efecto disparo contribuye a recrear la dimensión acústica del delito con la aparición de los que podríamos denominar 'crímenes sonoros'.

De hecho, el único tipo de asesinato que cumple de forma evidente la premisa de poder ser identificado como crimen sonoro en los episodios analizados es el provocado por disparo o detonación (a través de efecto sonoro). No obstante, en algunas ocasiones, ante otra clase de asesinatos, o en la propia muerte que el criminal consuma a través de disparo, se hace uso de otros recursos sonoros, como el grito de la víctima, sonido de cuerpo que cae, etc., aunque no en todos los episodios en los que la víctima muere por causa de arma de fuego existe recreación sonora del delito.

\section{Efecto sonoro disparo. Crimen sonoro}

\section{SONIDO: PASOS. VIENTO. SE APIANA}

ELISA.- Bueno, a ver si consiguen arreglar las cosas para que podamos seguir el viaje. Siete personas, viajaremos un poco más incómodos en un auto corriente, pero siempre es preferible pasar un rato de incomodidad, que pasarnos toda la noche aquí.

\section{ELISA.- ¡Ay! ¿Qué ha sido eso?}

\section{SONIDO: DISPARO LEJANO}

NORAH.- Un tiro. Alguien ha disparado aquí cerca.

ELISA.- Dios mío, ¿qué habrá pasado?

Guion: 7 de junio de 1958, 20.00 h. Episodio: "Un tiro en la noche”.

Una de las estrategias empleadas por el guionista es diseñar crímenes que se producen en el transcurso del episodio. En algunos casos, el autor introduce de forma explícita el sonido del disparo que provoca la muerte de la víctima, de manera que el oyente, y el resto de personajes que se encuentran en un escenario contiguo, puedan escuchar la ejecución del crimen, como se puede apreciar en el ejemplo anterior. De hecho, es poco habitual que los personajes presencien el asesinato en el momento en que se comete, aunque en determinados episodios sucede.

\section{Efecto sonoro disparo. Crimen sonoro}

\section{DISPARO DE REVÓLVER}

BANISTER: (GEMIDO)

\section{RUIDO DE CAÍDA POR LA ESCALERA}

KIRKWOOD: ¡Corten!.... ¿Todo ha ido bien, Sanders?

SANDERS: Lo siento, señor Kirkwood, pero será necesario rodar de nuevo la escena.

(...)

TAXI: Me temo, señor Kirkwood, que el pobre Banister no podrá volver a levantarse nunca más... ¡Está muerto! 


\section{DISERTACIONES}

ESTUDIOS

El papel del sonido en la comunicación: contribución, funciones y efectos

ISSN: $1856-9536$

Doi: http://dx.doi.org/10.12804/revistas.urosario.edu.co/disertaciones/a.6403

Volumen 12, Número 2 / Julio-diciembre 2019

Versión PDF para imprimir desde

http://revistas.urosario.edu.co/index.php/disertaciones

Resulta habitual a su vez que la muerte por disparo se introduzca y describa por medio de los diálogos de los personajes - que pueden ser complementados por la intervención del narrador-, en lugar de a través de efecto sonoro.

\section{Muerte por disparo sin efecto sonoro}

INS.: Bueno, continúo: si hemos de juzgar por la posición de la víctima y el ángulo de tiro, el disparo fue hecho desde la puerta de esta oficina. El asesino dejó aquí el arma, un revólver provisto de silenciador. ¿Está claro?

TAXI: Clarísimo, señor Inspector. Ha resumido usted muy bien los hechos.

Guion: 24 de marzo de 1951, 21.05 h. Episodio: “Crimen en la biblioteca pública”.

Por otra parte, también el intento de asesinato puede estar ambientado con efectos sonoros, así como otro tipo de hechos delictivos que no llegan a causar muertes. Esta clase de técnicas contribuyen a potenciar la vertiente sonora del género e incrementar el suspense, la sensación de intriga y amenaza.

\section{Efectos sonoros de hechos delictivos}

\section{SONIDO: RÁFAGA DE VIENTO}

NORAH.- (NARRA) Al cabo de un momento llegamos a la calle principal del pueblo.... Y vimos bajar por ella una camioneta de la que surgían fogonazos....

SONIDO: RÁFAGA DE AMETRALLADORA ESPACIADAS

GLOSS.- ¡Han instalado una ametralladora en la camioneta de la lavandería!

SONIDO: SE ACERCAN LAS RÁFAGAS DE AMETRALLADORA

NORAH.- ¡Pongámonos a cubierto.... en aquel portal!

SONIDO: RÁFAGAS AMETRALLADORA

Guion: 10 de agosto de 1967, 21.30 h. Episodio: "La aventura de la isla en peligro".

Junto al disparo (y el resto de efectos vinculados al hecho delictivo), no podemos obviar mencionar la presencia de otro efecto sonoro clásico en la ambientación de misterio, al que ya hemos hecho alusión en páginas previas (también con ejemplos): el trueno. Este efecto sonoro aparece en un $35 \%$ de los capítulos analizados. En aquellos episodios en los que está presente el trueno, este recurso cumple una doble o triple función. Por una parte, una función descriptivo-ambiental, puesto que recrea la tormenta que envuelve a los personajes y es de carácter diegético. Aparece generalmente cuando ya ha comenzado la noche o en el intervalo tarde-noche. La presencia de este tipo de efecto, al que suelen acompañar otros, como la lluvia o el viento, desempeña sin duda una función eminentemente expresiva, pues lo que se pretende es generar un clima de suspense y misterio en el que desarrollar el relato y sugestionar tanto a los personajes como a los oyentes. En tercer lugar, el trueno puede cumplir una función narrativa (transición entre escenas), lo hemos podido observar en los distintos ejemplos aportados. Así mismo, en los casos en los que el efecto trueno ejerce el papel de capper, revela un carácter diegético, puesto que forma parte de la historia. 
Finalmente, el efecto sonoro reloj aparece en un $25 \%$ de guiones. Se encuentra en minoría significativa con p $<0,01\left(\mathrm{Chi}^{2}=10,000 ; 1 \mathrm{gl} ; \mathrm{p}=0,002\right)$. Al comparar su presencia entre las épocas se observa una evidente disminución, significativa con $\mathrm{p}<0,001\left(\mathrm{Chi}^{2}=17,654 ; 2 \mathrm{gl} ; \mathrm{p}=0,000\right)$. Si en la primera etapa se emplea en dos tercios de los episodios, en la segunda la cifra desciende al 12,5\% y en la tercera el uso de este efecto ha desaparecido por completo.

Por otra parte, y desde un punto de vista formal, los efectos sonoros aparecen tanto de forma autónoma como combinados con otros elementos del lenguaje radiofónico, a través de fundidos, encadenados o superposición de varios elementos (con otros efectos, música, palabra...). En determinados instantes del relato aparecen en primer plano (transición entre escenas, aparición de un nuevo escenario, efecto de importancia por su fuerza expresiva, ambiental o narrativa...). Dichos efectos pueden desaparecer o mantenerse en la escena de fondo. También puede suceder que desde el inicio el efecto se encuentre en un plano de fondo. Del mismo modo, los efectos o bien redundan con información sonora lo explicitado por la palabra (contribuyendo a otorgar verosimilitud a la escena), o aportan nueva información a través de la representación sonora de un determinado objeto, acción, realidad, personaje o ambiente.

Debido a que en esta investigación presentábamos un interés especial por aquellos efectos que nos permitieran identificar el universo policíaco de la serie, cerraremos los resultados detallando un listado de algunos de los efectos más representativos registrados en el análisis que se encuentran relacionados con el género policíaco y la ambientación de misterio (ver tabla 4 y tabla 5).

Tabla 4. Efectos sonoros género policíaco en la serie Taxi Key

\section{Efectos sonoros género policíaco}

Disparo

Ruido de tiroteo; tiros

Detonaciones

Ráfaga de ametralladora (tableteo ametralladora)

Ruido pistola al caer al suelo

Puñetazo

Ruido de lucha

Ruido pelea

Ruido de bofetada

Explosión; explosión ahogada

Ruido fuerte y lejano de coche que vuelca

Ruido de un cuchillo al clavarse en madera

Silbido de lanza (y golpe al clavarse esta)

Golpe de cuerpo al caer al suelo; ruido de cuerpo que cae; estruendo cuerpo cae; ruido de derrumbarse cuerpo

Ruido de caída lejana; ruido caída por las escaleras

Porrazo fuerte

Golpe

Batacazo

(Efectos identificados con cadáver, en algún caso con desmayo, tropezar...)

Sirena policía; silbato policía

Ruido de forcejear con una puerta

Ruido arrastrarse por el suelo

Teclear de máquina de escribir (Comisaría/investigación)

Fuente: elaboración de la autora. 


\section{ESTUDIOS}

\section{DISERTACIONES}

El papel del sonido en la comunicación: contribución, funciones y efectos

ISSN: $1856-9536$

Doi: http://dx.doi.org/10.12804/revistas.urosario.edu.co/disertaciones/a.6403

Volumen 12, Número 2/ Julio-diciembre 2019

Versión PDF para imprimir desde

http://revistas.urosario.edu.co/index.php/disertaciones

Tabla 5. Efectos sonoros ambientación misterio en la serie Taxi Key

\section{Efectos sonoros ambientación misterio}

\section{Trueno}

Trueno fuerte

Viento lúgubre

Viento lejano

Viento fuerte

Viento tormentoso

Silbar del viento

Lluvia

Ruidos de la noche

Campanadas lúgubres

Campanadas del Big Ben

Campanadas de niebla

\section{Chirrido puerta}

Chirrido prolongado y lúgubre

Aldabonazos a la puerta; aldabonazos bruscos y fuertes

Tic-tac metrónomo

Tic-tac reloj

Suena reloj carrillón dando las doce

Reloj de salón dando la hora

Pasos lejanos que se acercan

Pasos impresionantes

Pasos que se acercan corriendo

Pasos precipitados sobre madera

Pasos que se alejan

Pasos sigilosos

Rastrear de pies

Pasos de subir escalera (en situación de misterio)

Pasos precitados de bajar (en situación de misterio)

Pasos-crujido

Maullido fuerte

Ruido cristales rotos

Alarido fuerte

Golpes sobre madera

Crujido lejano

Crujidos de madera

Fuente: elaboración de la autora.

\section{Conclusiones}

El estudio demuestra que en Taxi Key se emplean tanto efectos sonoros de carácter general como sonidos vinculados al género policíaco y la ambientación de misterio. Prevalece el uso naturalista y carácter diegético de los efectos. En la primera etapa, la diversidad y utilización de efectos sonoros es significativamente mayor respecto a las otras dos. 


\section{DISERTACIONES}

ESTUDIOS

El papel del sonido en la comunicación: contribución, funciones y efectos

ISSN: 1856-9536

Doi: http://dx.doi.org/10.12804/revistas.urosario.edu.co/disertaciones/a.6403

Volumen 12, Número 2 / Julio-diciembre 2019

Versión PDF para imprimir desde

http://revistas.urosario.edu.co/index.php/disertaciones

- Prevalece la función ambiental o descriptiva (o descriptivo-ambiental) de los efectos sonoros en todos los episodios. Resulta especialmente significativa en la construcción y recreación de los escenarios.

- La función narrativa de los efectos es la segunda modalidad más presente en los guiones de la serie y aparece representada de forma mayoritaria en su vertiente de transición espacio-temporal entre escenas. También se registra el empleo de esta función en su variante de reconstruir acciones o identificar personajes, aunque en menor medida en este último caso.

- La función expresiva de los efectos sonoros aparece en tercer lugar. Se le otorga mayor grado de protagonismo en determinados guiones y resulta indispensable en la creación de suspense, intriga y misterio. Los sonidos que desempeñan esta función ejercen de forma simultánea una función descriptivo-ambiental, a la que se puede adicionar la narrativa. Destaca en este contexto la utilización de efectos vinculados a la tormenta.

- Los efectos sonoros aparecen tanto de forma autónoma como junto a otros elementos del lenguaje radiofónico, en primer plano o de fondo. Se ha detectado como técnica frecuente que un mismo efecto sonoro cumpla en la historia más de una función simultáneamente.

- Entre los tipos de efectos más frecuentes, de los tipificados en el instrumento, se sitúan el efecto puerta, pasos y motor de auto. Otros efectos habituales en la serie que representan sonidos clásicos del género policíaco y la ambientación de misterio son el disparo y el trueno. Como sonidos recurrentes, de carácter general, aparecen a su vez el teléfono, el timbre y el frenazo.

- La presencia del efecto disparo/detonación fomenta la aparición de crímenes sonoros y contribuye a recrear la dimensión acústica del delito. Aparecen a su vez otros recursos que favorecen la representación sonora de los hechos delictivos.

- Existen diversos factores de carácter narrativo que pueden limitar la presencia de efectos sonoros vinculados al delito. Entre estos condicionantes se encuentra el punto de vista desde el que el oyente percibe el relato, la omisión de la escena del crimen perpetrado durante el episodio o el diseño de hechos delictivos consumados de forma previa al inicio de la historia que no se retoman a través de flashback.

\section{Referencias}

1. Aguilera, M., \& Arquero Blanco, I. (2017). La ficción sonora y la realización en directo: el reto de RNE. Área Abierta. Revista de Comunicación Audiovisual y Publicitaria, 17(1), 117-146. Recuperado de https://revistas. ucm.es/index.php/ARAB/article/view/54404

2. Balsebre, A. (2002). Historia de la radio en España. Vol. II (1939-1985). Madrid: Cátedra.

3. Balsebre, A. (2007). El lenguaje radiofónico. Madrid: Cátedra.

4. Barea, P. (1994). La estirpe de Sautier. La época dorada de la radionovela en España (1924-1964). Madrid: El País Aguilar.

5. Casetti, F., \& Di Chio, F. (1999). Análisis de la televisión. Instrumentos, métodos y prácticas de investigación. Barcelona: Paidós.

6. Chion, M. (1999). El sonido. Barcelona: Paidós. 


\section{DISERTACIONES}

ESTUDIOS

El papel del sonido en la comunicación: contribución, funciones y efectos

ISSN: $1856-9536$

Doi: http://dx.doi.org/10.12804/revistas.urosario.edu.co/disertaciones/a.6403

Volumen 12, Número 2 / Julio-diciembre 2019

Versión PDF para imprimir desde

http://revistas.urosario.edu.co/index.php/disertaciones

7. García, Ma. C., \& Berganza Ma. R. (2005). El método científico aplicado a la investigación en comunicación mediática. En Ma. R. Berganza \& J. A. Ruiz San Román (Coords.), Investigar en comunicación: guía práctica de métodos y técnicas de investigación social en comunicación (pp. 19-42). Madrid: McGraw-Hill.

8. Guarinos, V. (2009). Narrativa radiofónica. Madrid: Síntesis.

9. Gutiérrez, M., \& Perona, J. J. (2002). Teoría y técnica del lenguaje radiofónico. Barcelona: Bosch.

10. Hernández Sampieri, R., Fernández Collado, C., \& Baptista Lucio, P. (2010). Metodología de investigación. México: McGraw-Hill.

11. Igartua, J. J. (2006). Métodos cuantitativos de investigación en comunicación. Barcelona: Bosch Comunicación.

12. Kaplún, M. (1978). Producción de programas de radio. Quito: Ciespal.

13. Martínez-Costa, M. P., \& Díez Unzueta, J. R. (2005). Lenguaje, géneros y programas de radio. Introducción a la narrativa radiofónica. Pamplona: EUNSA.

14. Merayo, A., \& Pérez, C. (2001). La magia radiofónica de las palabras. Aproximación a la lingüística en el mensaje de la radio. Salamanca: Librería Cervantes.

15. Ortiz Sobrino, M. A., \& Volpini, F. (2017). Realización, lenguaje y elecciones narrativas de radioteatro: tres aproximaciones a la creación de espacios sonoros en el tiempo. Área Abierta. Revista de Comunicación Audiovisualy Publicitaria, 17(1), 13-36. Recuperado de https://revistas.ucm.es/index.php/ARAB/article/view/53496

16. Ortiz, M. A., \& Volpini, F. (1998). Diseño de programas en radio. Guiones, géneros y fórmulas. Barcelona: Paidós.

17. Pousa, X. R., \& Yaguana, H. A. (2013). La radio, un medio en evolución. Salamanca: Comunicación Social.

18. Radio Barcelona. (1925-1958). Colección de guiones de la programación diaria de Radio Barcelona (19251958). [Manuscrito]. Barcelona: Universidad Autónoma de Barcelona, Biblioteca de Comunicación y Hemeroteca General.

19. Radio Barcelona. (1950-1966). Colección de guiones de Taxi Key. [Manuscrito]. Barcelona: Archivo de Radio Barcelona-Cadena SER.

20. Rodero, E. (2011). ¿Veo cuando oigo? Recursos sonoros para estimular la creación de imágenes mentales en el oyente. Portal de la Comunicación InCom-UAB. Lecciones del portal. Recuperado de http://www.portalcomunicacion.com/uploads/pdf/63_esp.pdf

21. Rodero, E. (2005). Producción radiofónica. Madrid: Cátedra.

22. Soengas, X. (2010). Utilización del lenguaje radiofónico en los relatos de ficción. En E. Rodero \& X. Soengas, Ficción radiofónica: cómo contar una historia en la radio (pp. 151-187). Madrid: Instituto RTVE.

\section{Anexo}

Ejemplos de efectos sonoros en muestra de guion radiofónico de la serie Taxi Key (Programa: ¿Es usted buen detective?). Fecha: 7 de octubre de 1950. Hora de emisión: 21.00 h. Título del episodio: "La presencia invisible” (se adjunta: p. 2 y p. 8). Episodio número 111. Emisora: Radio Barcelona. Sociedad Española de Radiodifusión. Guion: Luis G. de Blain.

Fuente: Colección de guiones de la programación diaria de Radio Barcelona (1925-1958). [Manuscrito]. Biblioteca de Comunicación y Hemeroteca General de la Universidad Autónoma de Barcelona. 
GLOSSOR: Jistas campanedas de 1 a Torre de Lonores tienen un sonido siniestro.

TEXI: Particularmente cuando suenen on una noche de niebla.

WORAl: Afortunadamente, hoy tenenos luna liena

TAXI: Thueno, Glossop,

aLos.: A casa de une tie mia, una señora algo entrada en años y un poco excentrics.

MORAL: ICaramba!

GLOS,: Tịve en uno de 10 s barrios más entoguos de Jondres, su casa es viejis sima.

TaxI: To me gusta.

GLoS.: 3 que es 10 que no te gusta?

Taxi: Isa casa.

Gros.: Pues te advierto, Texi, que es casi un momumento historico.

IAXI: Wunca he sentido debilidad por los monumentos hi sto ricos... ¿que te parece, Norah, ai. no fuesemos a aquel cabsret de Piccadylly?

NORA: $\mathrm{Bs}$ un luger muy divertido.

Gtos.: Ith 1 ... No podeis hacerme eso. Te prometí a mi tia que os llevarie ëstanoche a su casa..... Precísenente, ya hemos l.legado!

MOTOR $=$ CESA

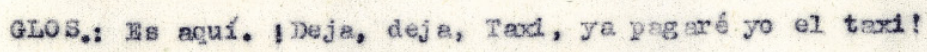

KUIDO TR AFICO, BUT AWO

WORAH: Wo me gusta nada el ampecto de esta casa.

IAXI: si por dentro es iguel que por fuera.

Gros.: Lo es... ma mobiliexio pxoviene de log timpos de la Reine victoria....ty se elumbran con luz de gas!

WOR Al: |Brrxre|

IAXI: Ya veo que tu tia ex una original.

GLOS: SA, pero es I rmeneamente ríca.

ITORAK: I Ah, caramba!

GLO S.: T.l amaxé

ALDABOA

TAXI: \&Tu tia Vive sola?

GLOS.: No... Viren con ella su nieto unico, Ferold, un secretario y un tipo raro, una especie de poeta o cosa por el estilo, a quien mi tia protege.

TOR All: Chist, que vienen a tore obrix!

BLOR: Bvenos noches, señor Glossop...I Paละท ustedes!

PORI AZO= CSSA IRASICO 


\section{DISERTACIONES}

ESTUDIOS

El papel del sonido en la comunicación: contribución, funciones y efectos ISSN: $1856-9536$

Doi: http://dx.doi.org/10.12804/revistas.urosario.edu.co/disertaciones/a.6403

Volumen 12, Número 2 / Julio-diciembre 2019

Versión PDF para imprimir desde

http://revistas.urosario.edu.co/index.php/disertaciones
1.

GLOS.: ino !

IAXI: Isube 1 a escelera te digo, y no seas kiedoso, que no to va a
pasar nocis

GLos: st no hay peligro..., d por que no 2 e subes tu mi mo?

TAxx: Porque tengo que vigilar 20 que pasa en la escalere. Comprenderes que no vucio subj $x$ estudiar el propio tiemo el fenomeno de 20 s pasos uni aterioso.

Gios.: Betá bien, por eso no be preocupes. I Tu suber y yo egtudi aré ! MORAlit i Perece mentixs que seas tan apocorio, Glossopl... No pretenderás que suba yo.

GLoS $:$ i Ah, puea no es una mala idea!... Tu subes y nosotros vigil amos. IAXI: fGloseop!, ano te dé verguenze?

GLos.: No.

THOR AHE 1 GLOSOO !

Gto\$.: Bgtá bien... No as nece sario que insistais... I Subiré yo!

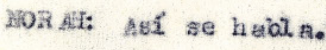

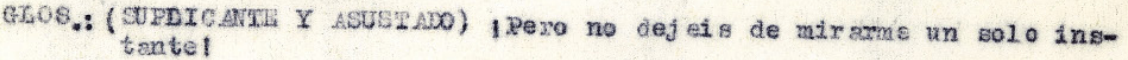

TANI: IVemos, sube do una vea!

GLOS: Yo vay.

TAXI: ( ACZ ANDO GA VOZ) \& Te sigue aiguien?

GLOS.: (ALGO TaJOS) Todaria no.

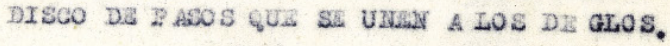

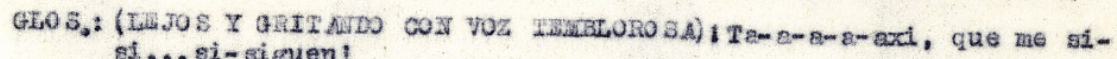
st.... si-siguen!

TAKI: I No te detengag, sigue subiendo !

aros: (IDan) the str. sioguent

WOR Ais Pues en 2 a escal exa no hey nadie.

CIISAI DASOS Y DISCO

INXI: (ALZ ABDO I.A VOZ) \&Has 21 egado ya axriba?

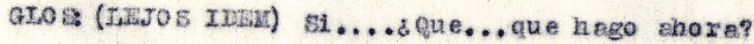

TAXI: $B \Omega^{j} 2$.

GLOS.: con mucho guato

PASOS PREOTPITADOS DE BH AR = CASAN

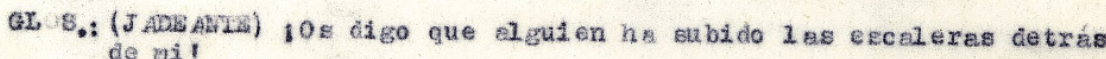
de mi!

TAXI: \&\$stae seguro?

GLoS.: 1 Seguxisimo $1 . . .01$ perfectanente el ruido de 10 p pasos subiendo 1 a escalem

WOR Ail: frues no so tros no hemo's visto a nadie! 